\title{
Exacerbation of Antigen-induced Arthritis in Urokinase-deficient Mice
}

Nathalie Busso, Véronique Péclat, Karen Van Ness, Eric Kolodziesczyk, * Jay Degen, ${ }^{\ddagger}$ Thomas Bugge, ${ }^{\ddagger}$ and Alexander So

Centre Hospitalier Universitaire Vaudois, Laboratoire de Rhumatologie, 1011 Lausanne, Switzerland; *Nestec Ltd. Research Centre, 1026 Lausanne, Switzerland; and ${ }^{\ddagger}$ Division of Developmental Biology, Children’s Hospital Research Foundation, Cincinnati, Ohio 45229

\section{Abstract}

In rheumatoid arthritis, synovial expression of urokinase (uPA) activity is greatly increased (Busso, N., V. Péclat, A. So, and A.-P. Sappino. 1997. Ann. Rheum. Dis. 56:550557). We report the same effect in murine antigen-induced arthritis. uPA-mediated plasminogen activation in arthritic joints may have deleterious effects via degradation of cartilage and bone matrix proteins as well as beneficial effects via fibrin degradation. We evaluated these contrasting effects in vivo by analyzing the phenotype of uPA-deficient (uPA $-/-$ ) and control mice during antigen-induced arthritis.

Joint inflammation was comparable in both groups up to day 3 and subsequently declined in control mice, remaining significantly elevated in uPA $-I-$ mice on days 10 and 30 after arthritis onset. Likewise, synovial thickness was markedly increased in uPA-deficient mice persisting for up to 2 mo, whereas it subsided in control animals. Bone erosion was exacerbated in uPA $-/-$ mice on day 30 . By contrast, no difference in articular cartilage proteoglycan content was found between both groups. Significantly increased accumulation of fibrin was observed by day 30 in arthritic joints of uPA $-I-$ mice. We hypothesized that synovial fibrin deposition plays a role in joint inflammation. Accordingly, defibrinogenation of $\mathrm{uPA}-I-$ mice by ancrod significantly decreased the sustained joint inflammation. All the above observations were reproducible in plasminogen-deficient (Pln-I-) mice.

In conclusion, synovial fibrin deposition plays a role as a nonimmunological mechanism which sustains chronic arthritis. (J. Clin. Invest. 1998. 102:41-50.) Key words: fibrin • inflammation • arthritis • urokinase $\cdot$ plasmin

\section{Introduction}

Rheumatoid arthritis (RA) is a systemic chronic inflammatory disease characterized by synovial hyperplasia and inflammatory cell recruitment, intraarticular fibrin deposition, and, in its later stages, cartilage and bone destruction (1). Extracellular matrix degradation is associated with at least two of these important features, namely intraarticular fibrin dissolution and

Address correspondence to Nathalie Busso, Centre Hospitalier Universitaire Vaudois, Laboratoire de Rhumatologie, Beaumont 02-224, 1011 Lausanne, Switzerland. Phone: 41-21-314-14-43; FAX: 41-21314-15-33; E-mail: Nathalie.Busso@chuv.hospvd.ch

Received for publication 16 April 1998.

J. Clin. Invest.

(C) The American Society for Clinical Investigation, Inc. 0021-9738/98/07/0041/10 \$2.00

Volume 102, Number 1, July 1998, 41-50

http://www.jci.org joint destruction. The urokinase (uPA) ${ }^{1} /$ plasmin system could represent an important pathway in these degradative processes.

uPA, which is secreted as an inactive single-chain protein (pro-uPA) and then converted into the two-chain active enzyme, is a highly specific serine protease catalyzing the conversion of plasminogen (Pln) into the broadly reactive protease plasmin $(2,3)$. Pro-uPA and uPA can bind to a specific, highaffinity cell surface receptor, uPAR (4); binding of UPA to UPAR increases the rate of Pln activation and greatly enhances extracellular matrix degradation and cell invasion (5).

uPA is expressed in vitro by almost all cells present in RA joints, such as synoviocytes, chondrocytes, and inflammatory cells (6). In RA synovial tissues, uPA activity, together with its corresponding antigen and mRNA, was increased compared with normal or noninflammatory osteoarthritic synovial tissues and was mainly associated with the synovial lining layer (7-9). RA synovial fluids also reflected such increased uPA levels (10-12).

Joint damage in arthritis, with cartilage and bone destruction, is believed to be mediated mainly through the release of neutral proteases such as metalloproteases (MMPs) and plasmin (13). uPA-mediated Pln activation could play a pivotal role in this degradative process as plasmin can directly degrade cartilage proteoglycans as well as other cartilage and bone matrix proteins, or indirectly, through the activation of latent MMPs $(14,15)$. Indeed, a contribution of uPA to cartilage and bone destruction has been shown in different in vitro experimental models $(16,17)$.

uPA-mediated Pln activation may also have a prominent role in intraarticular fibrin degradation. Accumulation of intraarticular fibrin, resulting from the altered balance between coagulation and fibrinolysis, is a common feature of RA $(8,18$, 19). Intraarticular fibrin deposits can have potential adverse effects (18). In this context, degradation of fibrin matrix, which is mainly performed by plasmin (20), could be beneficial; the most tangible evidence of ongoing plasmin-mediated fibrinolysis is the generation of specific fibrin degradation products such as fibrin D-dimers. The presence of such fibrin D-dimers has been demonstrated in RA synovial tissues and fluids (8, 19). Although the role of uPA in intraarticular fibrin removal has not been assessed in vivo, the concomitant presence of fibrin D-dimers and increased UPA activity in RA synovial tissues suggests ongoing uPA-mediated fibrinolysis in RA joints.

Besides its plasmin-dependent effects, uPA demonstrates effects upon binding to UPAR which are independent of its proteolytic activity such as mitogenic (21), migratory (22), and adhesiveness (23) responses. Some of these effects may be po-

1. Abbreviations used in this paper: AIA, antigen-induced arthritis; mBSA, methylated BSA; MMP, metalloprotease; PA, plasminogen activator; Pln, plasminogen; ${ }^{99 \mathrm{~m}} \mathrm{Tc},{ }^{99 \mathrm{~m}}$ technetium pertechnetate; tPA, tissue-type plasminogen activator; uPA, urokinase; uPAR, urokinase receptor. 
tentially relevant to some of the observed anomalies in RA synovium.

The relative importance of the contrasting roles of uPA in RA pathogenesis (deleterious with respect to joint destruction, beneficial in the context of fibrin-mediated inflammation) needs to be assessed in vivo. Using a murine model that recapitulates some of the histological and functional alterations of RA, we have explored the phenotype of the previously established uPA-deficient mice (24) in order to clarify the uPA role(s) in arthritis. Moreover, mice genetically deficient in Pln (25) provided an opportunity to evaluate the contribution of uPA-mediated Pln activation to these effects.

\section{Methods}

Animals. uPA-deficient mice (uPA-/-) and control mice $(\mathrm{uPA}+/+)$ both of a mixed Ola129 $\times$ C57BL/6 background (24), were originally provided by Dr. Carmeliet (University of Leuven, Belgium). Pln-deficient mice (Pln $-/-, 25)$ have been backcrossed to C57BL/6J for six generations (26). Heterozygous (Pln $+/-$ ) and wild-type $(\mathrm{Pln}+/+)$ littermates were used as controls. All these mice were of the haplotype $\mathrm{H}-2 \mathrm{~b}$, and were $8-12 \mathrm{wk}$ of age at the start of the experiment. The genotype of all the mice used was confirmed at the end of the experiments by zymography (uPA-/- mice) or by PCR analysis of genomic DNA extracted from mice tails (Pln-/-, 25).

Induction of arthritis. Antigen-induced arthritis (AIA) in mice was established as described previously (27). Briefly, mice were immunized on days 0 and 7 with $100 \mu \mathrm{g}$ methylated BSA (mBSA; Sigma Chemical Co., Buchs, Switzerland) emulsified in $0.1 \mathrm{ml}$ complete Freund's adjuvant containing $200 \mu \mathrm{g}$ mycobacterial strain H37RA (Difco, Basel, Switzerland) by intradermal injection at the base of tail. At the same time points (i.e., on days 0 and 7) and as an additional adjuvant, $2 \times 10^{9}$ heat-killed Bordetella pertussis organisms (Berna, Bern, Switzerland) were injected intraperitoneally. Arthritis was induced at day 21 by intraarticular injection of $100 \mu \mathrm{g}$ of mBSA in $10 \mu \mathrm{l}$ sterile PBS into the right knee, the left knee being injected with sterile PBS alone. Institutional approval was obtained for these experiments.

Histological grading of arthritis. At least four mice per group were killed, and the knees were dissected and fixed in $10 \%$ buffered formalin for $4 \mathrm{~d}$. Fixed tissues were decalcified for $3 \mathrm{wk}$ in $15 \%$ EDTA, dehydrated, and embedded in paraffin. Sagittal sections $(6 \mu \mathrm{m})$ of the whole knee joint were stained with Safranin-O and counterstained with fast green/iron hematoxylin. Histological sections were graded by two observers unaware of animal genotype or treatment. Synovial membrane thickness was scored from 0 to $3(0=$ normal thickness, $1=$ synovial thickness less than the depth of the femoral epiphysis, 2 = equal, $3=$ more). Cartilage proteoglycan depletion, reflected by loss of Safranin-O staining intensity, was scored on a scale of 0 (fully stained cartilage) to 3 (totally unstained cartilage) in proportion to severity. Bone erosion was scored on a scale of 0 to $4(0=$ no erosion, $1=$ erosion of $\leq 25 \%$ of the femoral and tibial articular surface, $2=26-50 \%, 3=51-75 \%, 4=>75 \%$ ).

Cryostat section preparation. Dissected knees were embedded in Tissue-Tek OCT, then immediately frozen in precooled hexane and stored at $-70^{\circ} \mathrm{C}$ until use. Sections were cut on a motor-driven Leica cryostat with a retraction microtome and a tungsten carbide knife at a cabinet temperature of $-25^{\circ} \mathrm{C}$.

Tissue protein extract preparation. $1050-\mu \mathrm{m}$ cryostat sections of joint tissue were homogenized in $50 \mathrm{mM}$ Tris- $\mathrm{HCl}, \mathrm{pH} 7.5$, containing $110 \mathrm{mM} \mathrm{NaCl}, 10 \mathrm{mM}$ EDTA, and $0.1 \% \mathrm{NP}-40$. The homogenate was centrifuged at $4,000 \mathrm{~g}$ for $10 \mathrm{~min}$ at $4^{\circ} \mathrm{C}$ and the supernatant was stored at $-20^{\circ} \mathrm{C}$. Protein content of the tissular extracts was measured by the method of Bradford using BSA as a standard.

$P A$ enzymatic assays. Tissue protein extracts were analyzed by SDS-PAGE zymographies as described (28). Briefly, after SDS-PAGE of the samples, the gel was washed in Triton X-100 and layered over a casein underlay containing $2 \%$ nonfat dry milk, $0.9 \%$ agar, and $40 \mu \mathrm{g} /$ $\mathrm{ml}$ of purified human Pln in PBS (with $0.9 \mathrm{mM} \mathrm{Ca}^{2+}$ and $1 \mathrm{mM} \mathrm{Mg}^{2+}$ ). Histological zymographies were performed using a modified procedure of the standard protocol (28). Briefly, 10- $\mu \mathrm{m}$ unfixed, undecalcified cryostat knee sections were attached to a sellotape as described (29). The sections were applied onto an underlay containing the same mixture as described above and covered with a coverslip. Control experiments were carried out with underlay mixtures lacking Pln. To distinguish uPA from tissue-type PA (tPA), amiloride, a specific inhibitor of uPA enzymatic activity (30), was added in the mixture at $1 \mathrm{mM}$ final concentration. Underlays were incubated in a humidity chamber at $37^{\circ} \mathrm{C}$ for 3-4 h during which PAs diffused from the gel (gel zymography) or tissue (in situ zymography) into the underlay, converting Pln into plasmin, which in turn lysed the insoluble casein. Zones of Pln-dependent caseinolysis appeared as black areas when visualized under dark-ground illumination. Photographs were taken using dark-ground illumination.

Gelatinolytic assays. Gelatin zymography was performed essentially as described (31).

Isotopic quantification of joint inflammation. Joint inflammation was measured by ${ }^{99} \mathrm{~m}$ technetium pertechnetate $\left({ }^{99 \mathrm{~m}} \mathrm{Tc}\right)$ uptake in the knee joint as described (32). Briefly, mice were first sedated by intraperitoneal administration of sodium pentobarbital $(50 \mathrm{mg} / \mathrm{kg})$ and then injected subcutaneously in the neck region with $10 \mu \mathrm{Ci}{ }^{99 \mathrm{~m}} \mathrm{Tc}$. The accumulation of the isotope in the knee was determined by external gamma counting after $15 \mathrm{~min}$. The ratio of ${ }^{99 \mathrm{~m}} \mathrm{Tc}$ uptake in the inflamed arthritic knee versus ${ }^{99 \mathrm{~m}} \mathrm{Tc}$ uptake in the contralateral control knee was calculated. A ratio higher than 1.1 indicated joint inflammation.

Fibrin immunohistochemistry. Paraffin-embedded sections were deparaffinized and rehydrated, then incubated for $30 \mathrm{~min}$ at room temperature with 5\% BSA and $20 \%$ normal goat serum. Endogenous peroxidase activity was blocked with $3 \% \mathrm{H}_{2} \mathrm{O}_{2}$ for $10 \mathrm{~min}$. Slides were then overlaid with rabbit anti-mouse fibrinogen serum (diluted 1:1,000) for $30 \mathrm{~min}$ at room temperature. Bound antibodies were visualized using the avidin-biotin-peroxidase complex (Vectastain Elite ABC kit; Vector Laboratories, Burlingame, CA). The color was developed by 3,3'-diaminobenzidine (Sigma Chemical Co.) containing $0.01 \%$ hydrogen peroxide. After extensive washing in water, slides were counterstained with Papanicolaou and mounted in Merckoglass. Staining specificity was confirmed using, as primary antibodies, nonimmune rabbit serum or fibrinogen-preadsorbed immune serum. An incubation without the first antibody served as a negative control. To estimate fibrin(ogen) levels, noncounterstained tissue sections, magnified 61 times through a microscope (Reichert Jung, Wien, Austria), were scanned using a color Kappa CF15/3 camera (Kappa, Gleichen, Germany) and a Semper 6P image analysis software (Synoptics, Cambridge, UK). The region outside the area of interest was masked and the threshold was adapted automatically for each image. The results were expressed as the ratio between the number of pixels associated to immunoreactive regions and to the total area examined.

Systemic defibrinogenation. Preimmunized mice were anesthetized, their backs were shaved, and 14-d mini-osmotic pumps (model 2002; Alza Corp., Palo Alto, CA) filled with a buffered solution of $250 \mathrm{U} / \mathrm{ml}$ ancrod (Sigma Chemical Co.) were implanted subcutaneously into their backs (one mini-pump per animal). The insertion sites were then closed by sutures. The pumps deliver $0.5 \mu \mathrm{l} / \mathrm{h}$, so the mice received $3 \mathrm{U}$ ancrod/d. In control animals, buffer-filled mini-pumps were implanted. On day 3 of ancrod infusion, arthritis was induced by intraarticular injection of mBSA. After $10 \mathrm{~d}$ of arthritis, mice were killed, blood was taken from the inferior vena cava, and citrated plasma was prepared. Plasmatic fibrinogen levels were quantified by densitometric analysis of fibrinogen Western blot using the rabbit anti-mouse fibrinogen serum described above at a dilution of 1:1,000.

Statistical analysis. Wilcoxon's rank sum test for unpaired variable (two-tailed) was used to compare differences between groups. $P$ values $<0.05$ were considered significant. 


\section{Results}

$u P A$ activity is increased in arthritic synovial membrane. On day 10 of AIA, tissue extracts were prepared from nonarthritic (left knees) and arthritic (right knees) joints and analyzed by zymography (Fig. $1 A$ ). This allowed clear distinction between uPA and the other PA, tPA, which migrated at 48 and $72 \mathrm{kD}$, respectively. UPA activity was detectable in all the tissue extracts analyzed (20/20) and was increased in the arthritic samples compared with the contralateral nonarthritic samples. Under the same conditions, tPA activity was undetectable. The increase in uPA activity was specific, since the activity of gelatinases was comparable (for gelatinase B [MMP-9]) or slightly increased (for gelatinase A [MMP-2]) between involved and noninvolved joints (Fig. $1 \mathrm{~B}$ ). As expected, no uPA activity was detected in tissue extracts from knee joints of uPA-defi- cient mice (Fig. $1 A$, first two tracks). Moreover, no significant difference in gelatinase $\mathrm{A}$ and $\mathrm{B}$ activities could be found between uPA-deficient mice and background-matched control mice (Fig. $1 B$ ).

In situ zymograms performed on arthritic knee joint sections of wild-type mice (Fig. $1 C$ ) revealed in all specimens analyzed (10/10) areas of Pln-dependent caseinolysis over the synovial membrane (second column). No lysis over this area was observed in the absence of Pln (first column) even after a longer period of incubation. Addition of amiloride, an inhibitor of uPA enzymatic activity in the underlay mixture, almost totally inhibited this Pln-dependent caseinolytic activity (third column) indicating that the catalytic activity associated with arthritic synovial membrane was mediated mainly by uPA. Additional Pln-independent caseinolysis was found associated with bone marrow cells, both in arthritic and nonarthritic

A

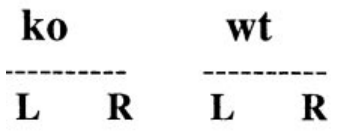

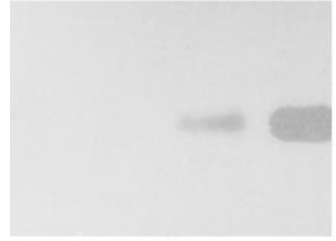

B

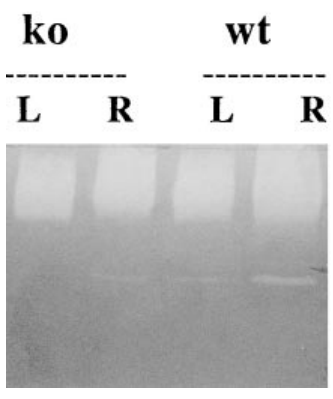

- MMP-9

- MMP-2 -tPA
-uPA

C -Pln + Pln + Pln + amiloride

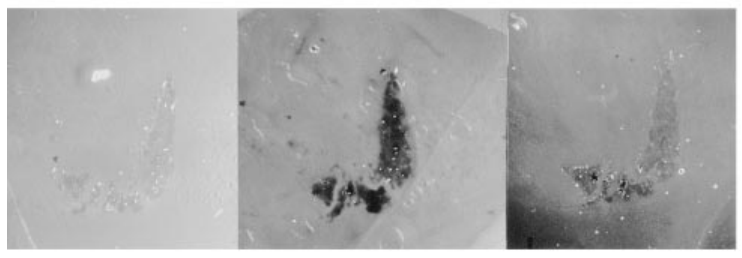

haematoxylin staining
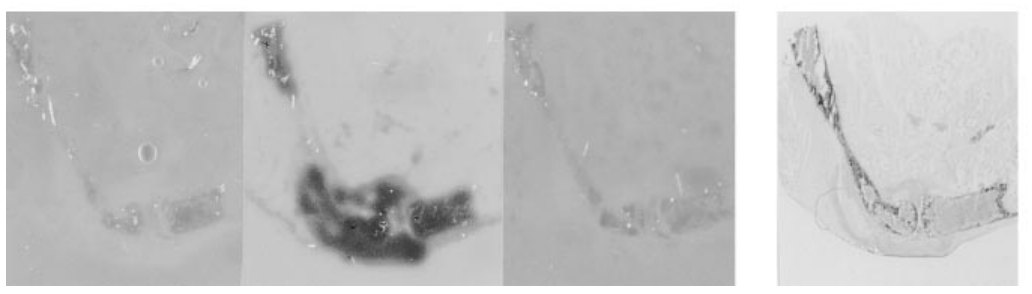

+ Pln + amiloride
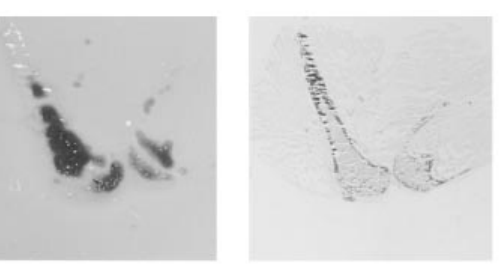

left knee (normal)
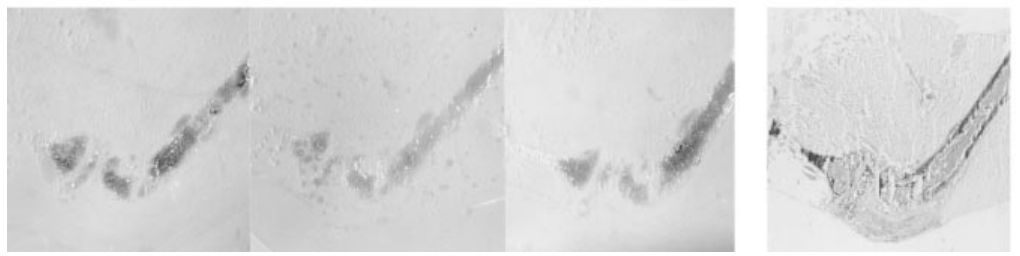

right knee (arthritic)

Figure 1. Enzymatic assays of knee synovial tissues. ( $A$ and $B$ ) Gel zymographies. $10 \mu \mathrm{g}$ of proteins from synovial tissue extracts of nonarthritic left $(L)$ and arthritic right $(R)$ knee joints was analyzed, after

right knee (arthritic) SDS-PAGE, by PA zymography $(A)$ and gelatinase zymography $(B)$. $w t$, wild-type mice; $k o$, uPA-deficient mice. ( $C$ and $D$ )

left knee (normal)
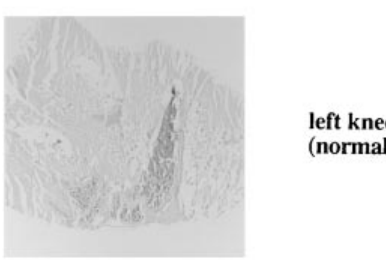
fied knee sections from wild-type animals $(C)$ or uPA-deficient animals $(D)$ were applied to an underlay containing Pln (second column). Control experiments were carried out with underlay mixtures from which Pln was omitted (first column). To distinguish uPA from tPA, amiloride, a specific inhibitor of uPA enzymatic activity, was added to the mixture (third column). Zones of caseinolysis appear as black areas when visualized under darkground illumination. 
a

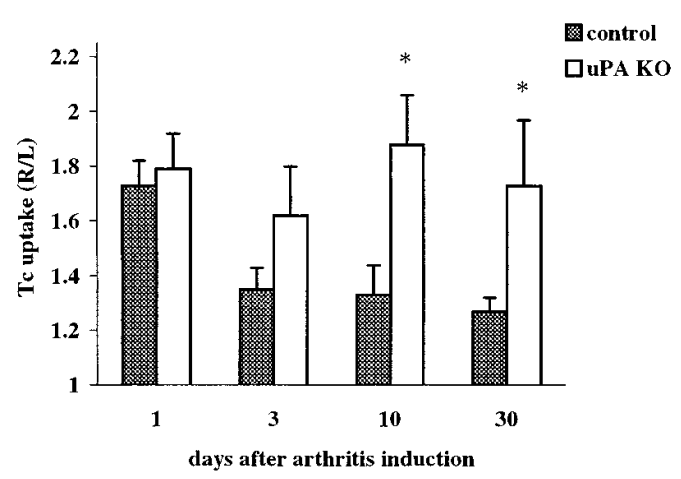

b

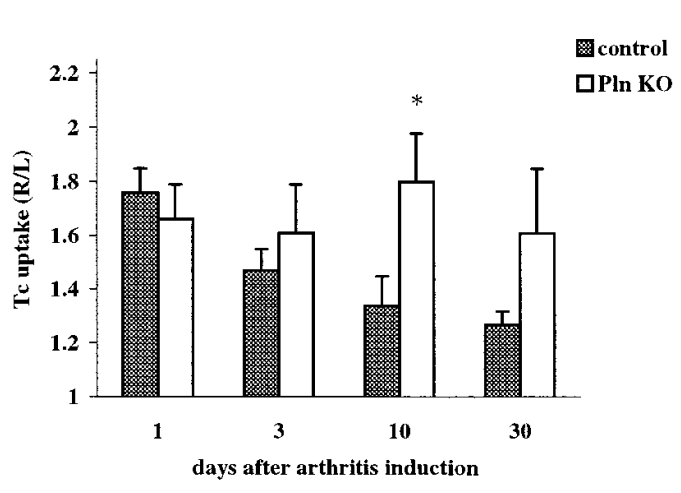

Figure 2. Time course of knee joint inflammation. Joint inflammation was measured by external gamma counting of ${ }^{99 \mathrm{~m}} \mathrm{Tc}$ uptake on different days after antigen challenge into the right knee. Results are expressed as the ratio of ${ }^{99 \mathrm{~m}} \mathrm{Tc}$ uptake in the right $(R)$ arthritic knee joint over the left $(L)$ noninflamed contralateral knee joint, a value higher than 1.1 indicating joint inflammation. (a) uPA-deficient

mice. (b) Pln-deficient mice. For each time point, mean \pm SEM of ratios from 4 to 14 mice per group is shown. Statistical significance was tested by using the Wilcoxon's rank sum test (deficient mice versus control mice). ${ }^{*} P<0.05$ was considered significant.

joints. In knee joints from uPA-deficient mice, only this Plnindependent activity could be evidenced (Fig. $1 \mathrm{D})$. This activity could not be observed by zymography of the corresponding tissue extracts (see Fig. $1 A$ ) due to its irreversible denaturation during SDS-electrophoresis.

UPA deficiency prolongs AIA-associated inflammation. To explore whether the observed increase in uPA activity in the arthritic joint had an effect on the course of AIA, we first measured knee joint inflammation in control and uPA-deficient mice. The severity of knee joint inflammation was evaluated by the ratio of ${ }^{99 \mathrm{~m}} \mathrm{Tc}$ uptake in the inflamed arthritic joint over that of the nonarthritic contralateral knee joint at different time points up to day 30 (Fig. 2). In control (uPA+/+) mice, maximal joint inflammation was reached $24-48 \mathrm{~h}$ after AIA, and began to decline thereafter (Fig. $2 a$ ). By contrast, in uPA-deficient mice, maximal joint inflammation was maintained until day 30 . The ${ }^{99 \mathrm{~m}} \mathrm{Tc}$ uptake was significantly greater in uPA $-/-$ mice on days 10 and $30(P<0.02)$. A similar persistence of inflammation was seen in Pln-deficient mice (Fig. $2 \mathrm{~b}$ ), suggesting that the prolonged inflammation observed in uPA-deficient animals is related to the absence of uPA-mediated conversion of Pln to plasmin.

uPA deficiency exacerbates histological features of AIA. To determine whether the observed persistence of knee joint inflammation in uPA-deficient mice was associated with specific histopathological changes, we compared the histological features of arthritic knee joints from control and uPA-deficient mice (Fig. 3). In both groups of animals, arthritis was histologically present in all knees which had been injected with mBSA. By day 3 of AIA, the synovial membrane of the arthritic knee was thickened and infiltrated with numerous granulocytes (results not shown). In wild-type mice, synovial membrane thickness remained increased until day 10 (Fig. $3 \mathrm{~A}$ ), after which it gradually subsided (see day 30, Fig. $3 C$ ). At day 60 , there were still some signs of synovial inflammation, but the thickness had nearly returned to normal (Fig. $3 E$ ). There was also an alteration in synovial inflammation, from the appearance of acute inflammation (day 3 ) to a more chronic inflammation characterized by a predominance of mononuclear cells (not shown). In uPA-deficient mice, synovial thickness was significantly increased in comparison of control mice $(P<$
0.02 ) by day 10 of AIA (compare Fig. 3, $A$ and $B$ ), and persisted beyond $60 \mathrm{~d}$ (compare Fig. $3, D$ and $F$ to $C$ and $E$, respectively, and see also the histological grading in Fig. $4 c$ ). Granulocyte and macrophage infiltration in the arthritic synovium from $\mathrm{uPA}-/-$ mice was comparable, on days 2 and 10 of AIA, to that from wild-type mice (as evaluated by immunostaining with a monoclonal antibody against murine Mac-1, data not shown). Finally, synovial fibrosis was evident in the arthritic joint of some uPA-deficient mice.

The effect of AIA on articular cartilage was evaluated (Fig. $4 a$ ). Induction of arthritis led to a decrease in proteoglycan content as demonstrated by loss of Safranin-O staining (compare the red proteoglycan staining of the articular cartilage matrix in nonarthritic control knee joint, Fig. $3 G$, with the corresponding staining in arthritic knee joints, Fig. 3, $A-F$, which was severely decreased or absent). This reduced proteoglycan staining, already noticeable on day 3 (not shown), was observed over the whole period of study in control mice. In uPAdeficient mice, similarly reduced proteoglycan staining was observed.

Bone erosion (Fig. $4 \mathrm{~b}$ ) was evident by day 3 of AIA in both groups of mice, and was significantly more pronounced in uPA $-/-$ mice on day $30(P<0.01)$. On day 60 , bone erosion was still severe in the uPA-deficient mice, but did not reach statistical significance.

Consistent with our earlier findings, like uPA-deficient mice, Pln-deficient mice developed significant synovial thickening that persisted for longer than in control animals (Fig. $4 f$ ) and exacerbated bone erosion (Fig. $4 e$ ). In addition, Pln-/and $\mathrm{uPA}-/-$ mice were similar with regard to the development of cartilage damage which did not significantly exceed that observed in control animals (Fig. 4, $a$ and $d$ ).

Increased fibrin deposition in arthritic joints of $u P A$-deficient mice. Based on the established role of Pln activation in fibrinolysis, we wished to test the hypothesis that the loss of uPA or Pln results in increased fibrin deposition. Fibrin content in knee joints was analyzed by fibrin immunohistochemistry (Fig. 5) and by morphometry (Fig. 6). The specificity of fibrin staining was demonstrated by the absence of signal obtained with normal rabbit serum or with immune serum preincubated with an excess of purified murine fibrinogen (results 

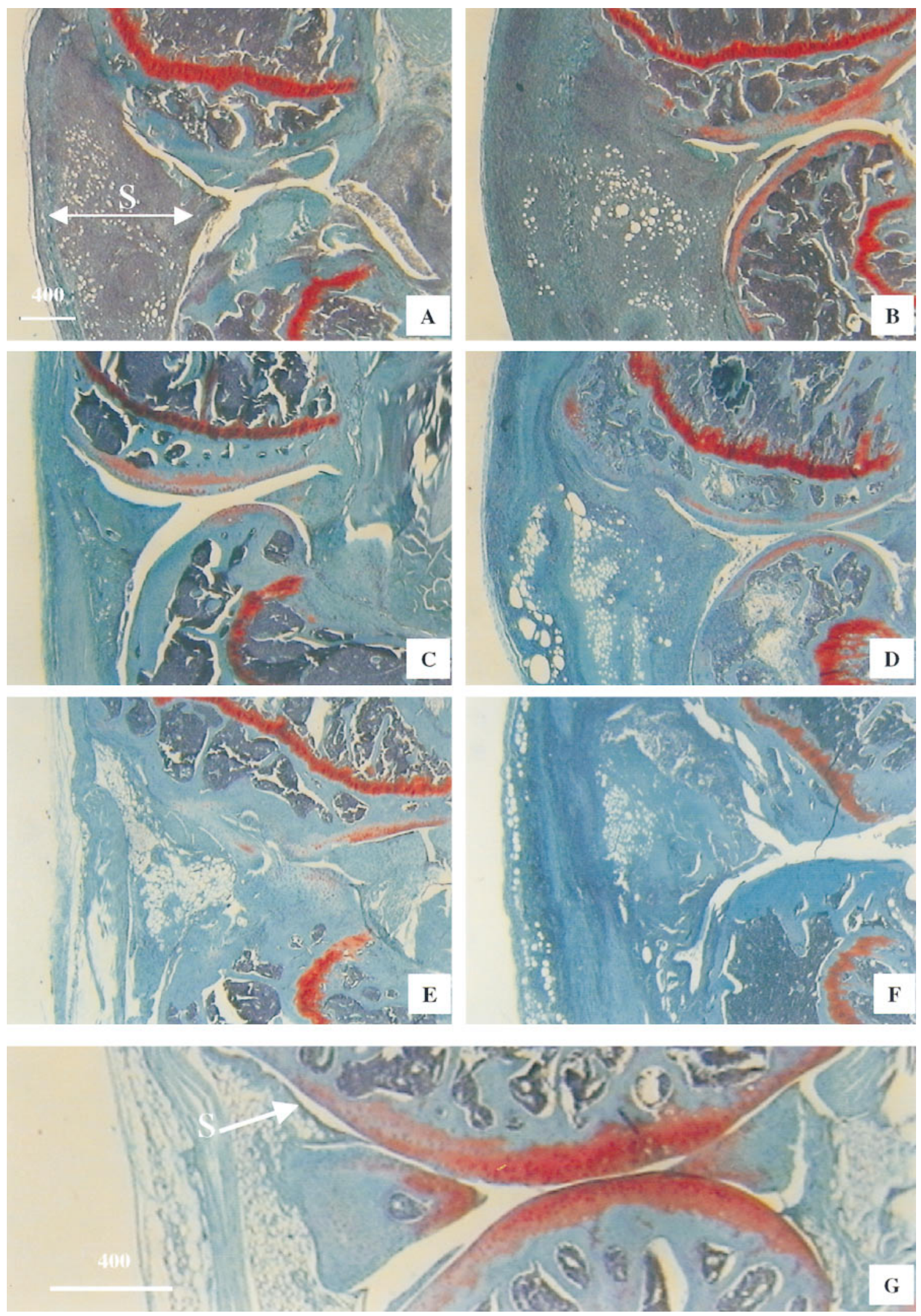

Figure 3. Histologies of whole knee joint sections stained with Safranin-O. Arthritic knee joints from wild-type mice on days $10(A), 30(C)$, and $60(E)$ after arthritis induction. Arthritic knee joints from uPA-deficient mice on days $10(B), 30(D)$, and $60(F)$ after arthritis induction. $(G)$ Nonarthritic control knee joint (injected with PBS). Note in the normal knee joint, the thin synovial membrane $(S)$ and the red proteoglycan staining of the articular cartilage matrix; in arthritic knee joints, this synovial membrane becomes hyperplastic and the red cartilage proteoglycan staining is severely decreased or absent (see $A$ ). 
a

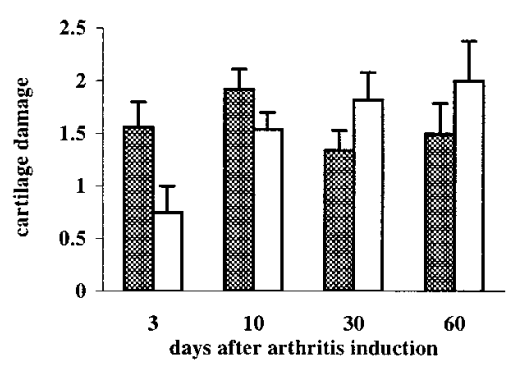

b

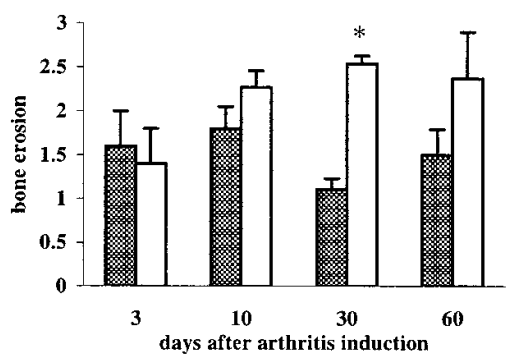

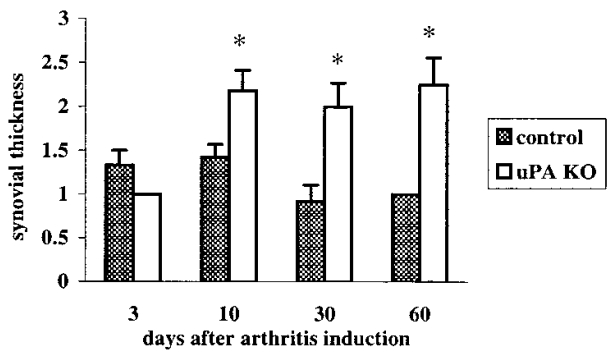

d

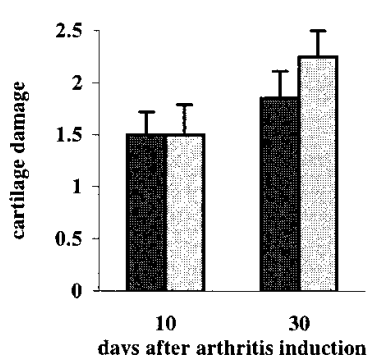

e

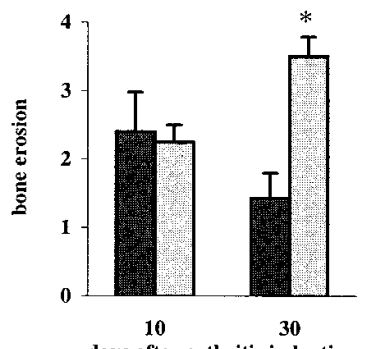

f

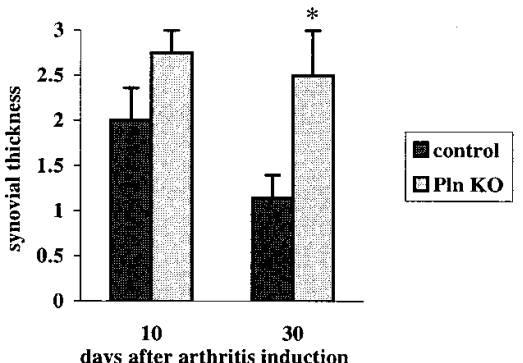

Figure 4. Histological scoring of arthritic knee joints. Cartilage damage, bone erosion, and synovial thickness were scored histologically using an arbitrary scale (see Methods) at different times after induction of arthritis. 4-12 mice per group were used for each time point. uPA-deficient mice (histograms $a-c$ ) and Pln-deficient mice (histograms $d-f$ ) were compared with background-matched control mice. Results are expressed as mean \pm SEM. Statistical significance was tested by using the Wilcoxon's rank sum test. $* P<0.05$ was considered significant.

not shown). In the normal nonarthritic knee joint, minimal fibrin immunoreactivity was found $(<1 \%$ of the total area examined, not shown). In arthritic uPA $+/+$ mice knee joints, fibrin was found in relatively low abundance $(<5 \%)$ on days 10 and 30 (Fig. 5, $A$ and $B$, and Fig. $6 a$ ). In contrast, increased amounts of fibrin were detected in $\mathrm{uPA}-/-$ at all time points studied (Fig. 5, $C$ and $D$ ). This difference was maximal at $30 \mathrm{~d}$ (20-fold increase versus control mice, $P<0.03$, Fig. $6 a$ ). A similar pattern of fibrin staining was obtained in the joints of Pln $-/-$ mice (Fig. 5, $E$ and $F$ ). Also in Pln $-/-$ mice, a statistically significant increase in fibrin accumulation was measured at $30 \mathrm{~d}$ (sixfold increase versus control mice, $P<0.05$, Fig. $6 b$ ).

Systemic fibrinogen depletion reduces joint inflammation in $u P A$-deficient mice. Induction of systemic coagulation by administration of the Malayan pit viper venom, ancrod, leads to consumption of systemic fibrinogen and is a means of reducing plasma fibrinogen levels (33). We hypothesized that under these conditions, excessive intraarticular fibrin deposition would be diminished and, as a result, fibrin-induced inflammation would be attenuated in uPA-deficient mice. Administration of ancrod $(3 \mathrm{U} / \mathrm{d})$ in these mice for $3 \mathrm{~d}$ before arthritis induction, and then throughout the experimental period, reduced plasma fibrinogen by $>80 \%$, without any effect on survival (results not shown). In accordance with the results above (see Figs. $5 C$ and 6), arthritic knee joints from nontreated uPA $-/-$ mice were strongly positive for fibrin(ogen) staining $10 \mathrm{~d}$ after induction of arthritis, whereas ancrod-treated uPAdeficient mice showed significantly reduced amounts of fibrin(ogen) immunopositivity (Table I). Finally, comparing ${ }^{99 \mathrm{~m}} \mathrm{Tc}$ uptake measurements in knee joints from ancrod-treated and untreated mice, we found that defibrinogenation significantly reduced, on day 10 of AIA, knee joint inflammation in $\mathrm{UPA}-/-$ mice $(P<0.02)$, whereas in the same conditions, it had no effect in wild-type mice (data not shown). This observation supports the potential pathogenic role of fibrin(ogen) in chronic joint inflammation associated to AIA in UPA-deficient mice.

\section{Discussion}

These studies demonstrate that uPA plays a protective role in arthritis by reducing joint inflammation, synovial thickness, and bone erosion. The exacerbation of joint inflammation (as measured by ${ }^{99 \mathrm{~m}} \mathrm{Tc}$ uptake) and of histological features of ar-

Table I. Effect of Systemic Fibrinogen Depletion on Joint Inflammation

\begin{tabular}{lcc}
\hline & $\begin{array}{c}\text { Untreated } \\
\text { UPA KO mice }\end{array}$ & $\begin{array}{c}\text { Ancrod-treated } \\
\text { uPA KO mice }\end{array}$ \\
\hline Intraarticular fibrin content & $100 \pm 9$ & $46 \pm 4^{*}$ \\
(\% untreated mice) & $(n=6)$ & $(n=5)$ \\
Joint inflammation & $1.85 \pm 0.10$ & $1.36 \pm 0.08^{*}$ \\
$(n=5)$ & $(n=5)$ \\
\hline
\end{tabular}

uPA-deficient mice were implanted $3 \mathrm{~d}$ before arthritis induction with ancrod-filled mini-osmotic pumps ( $3 \mathrm{U} / \mathrm{d}$ over $13 \mathrm{~d}$ ) or with bufferedfilled pumps. Mice were analyzed for intraarticular fibrin content and ${ }^{99 \mathrm{~m}}$ Tc uptake after $10 \mathrm{~d}$ of arthritis. Results are expressed as mean \pm SEM. $* P<0.03$ (nonparametric Wilcoxon test). 
Day : 10
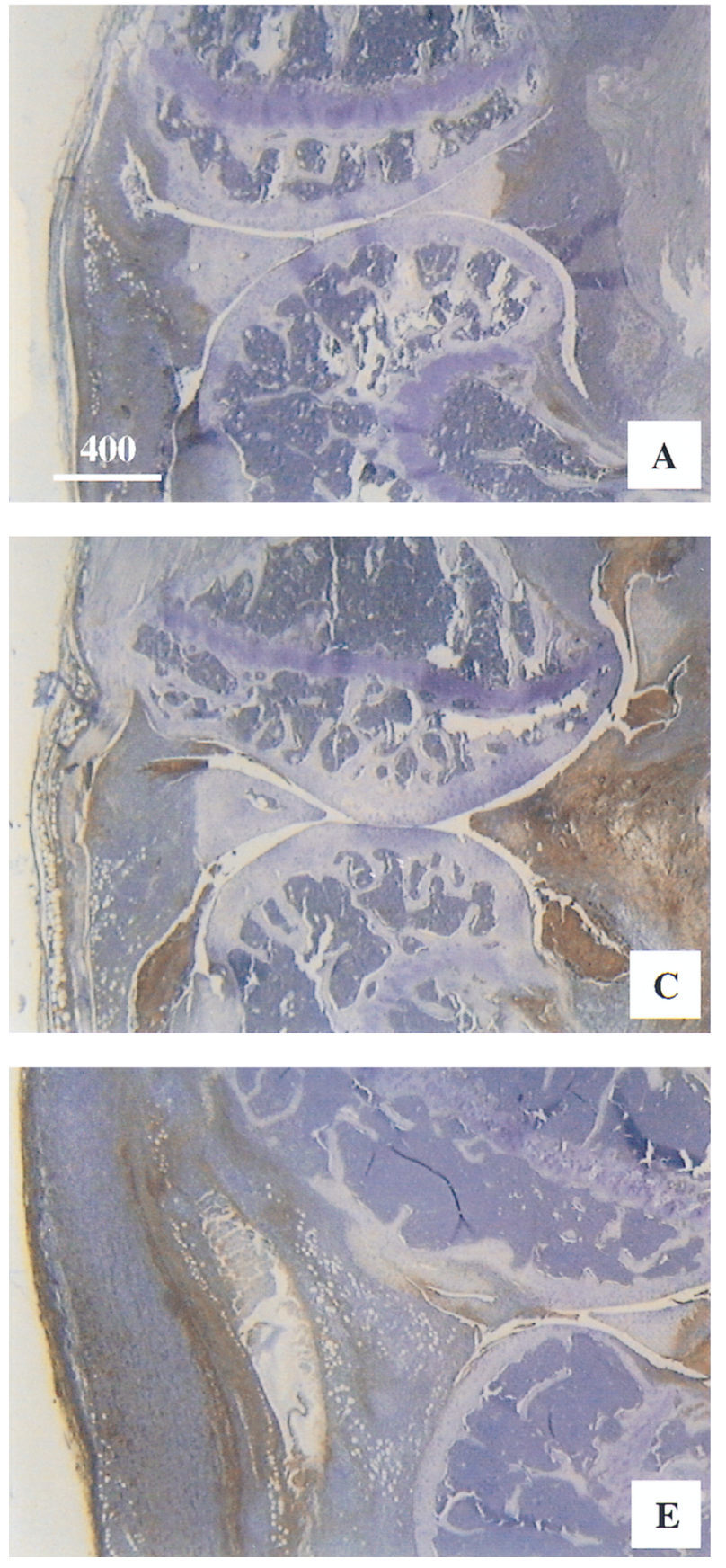

30

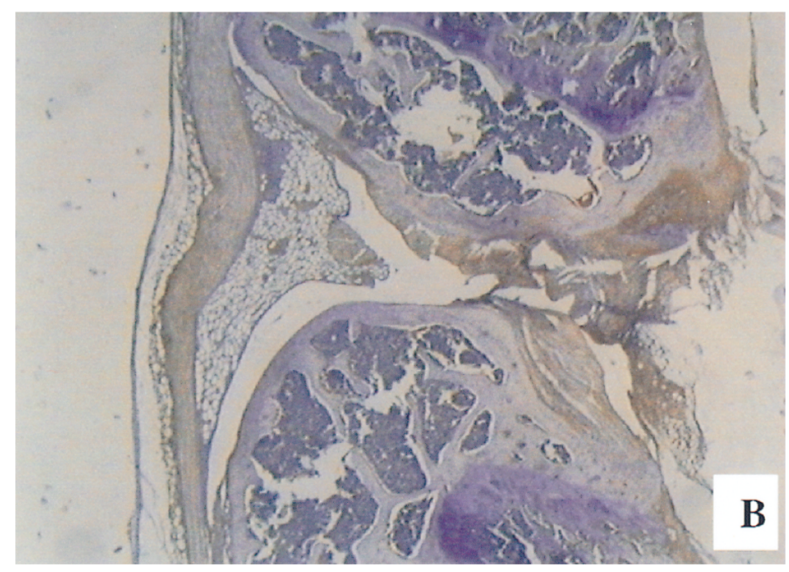

C

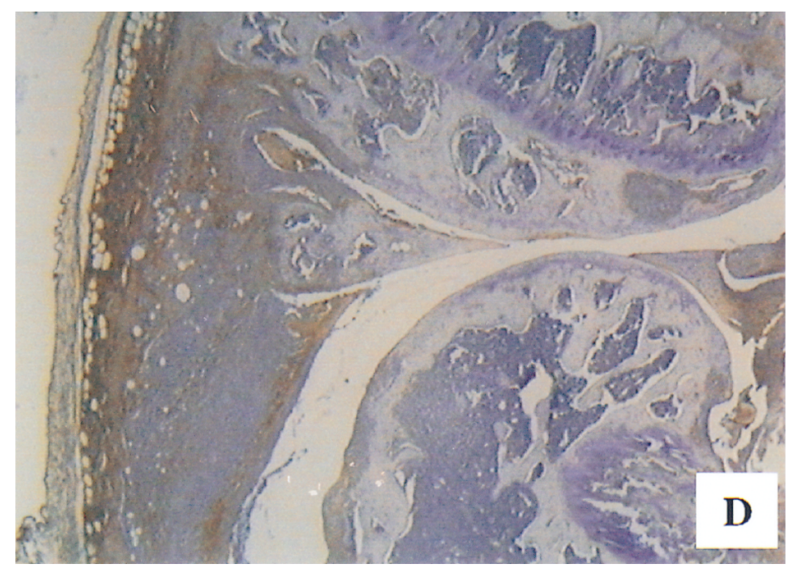

uPA

KO

Figure 5. Immunohistochemical detection of fibrin in arthritic knee joints. Paraffin-embedded tissue sections were stained with a rabbit antimurine fibrin(ogen) antibody. Brown color indicates positivity. Arthritic right knee joints on days 10 (left) and 30 (right) after arthritis induction of uPA $+/+$ control mice (from Ola129 $\times$ C57BL/6 background, $A$ and $B$ ), uPA-deficient mice $(C$ and $D$ ) and Pln-deficient mice (from C57BL/6 background, $E$ and $F$ ). Immunohistochemical stainings of Pln $+/+$ mice were not significantly different from those of uPA $+/+$ mice (not shown).

thritis in uPA-deficient mice was reproduced in Pln-deficient mice. This indicates that between the two pathways of Pln activation (uPA- or tPA-mediated), uPA-mediated Pln activation is the major one in the joint. This conclusion is supported by zymographic analysis of arthritic knee joints of wild-type mice which only showed uPA activity. Interestingly, in synovial tissues of RA patients, uPA activity was also predominant (7) due to increased antigenic levels of UPA and UPAR with concomitantly decreased tPA levels $(8,9)$. Finally, the fact that the phenotypes of uPA and Pln-deficient mice were similar rules out, in this animal model, the existence of plasmin-independent uPA effects, as have been reported previously in different in vitro studies (21-23).

Accumulation of extravascular fibrin in RA tissues repre- 
a

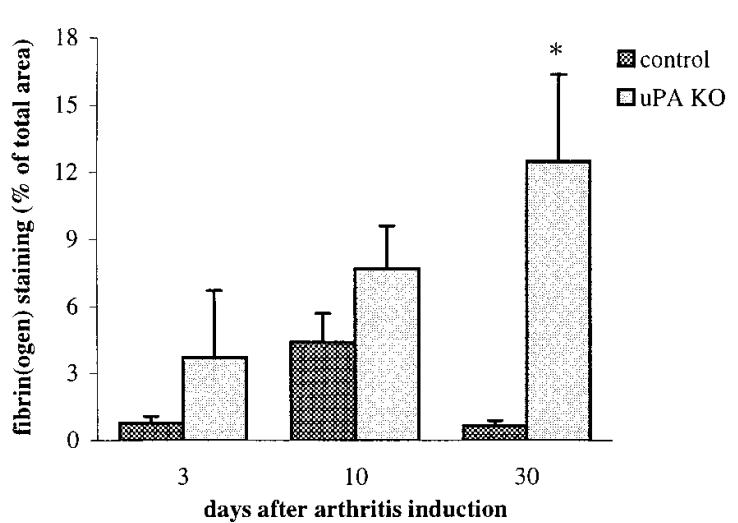

b

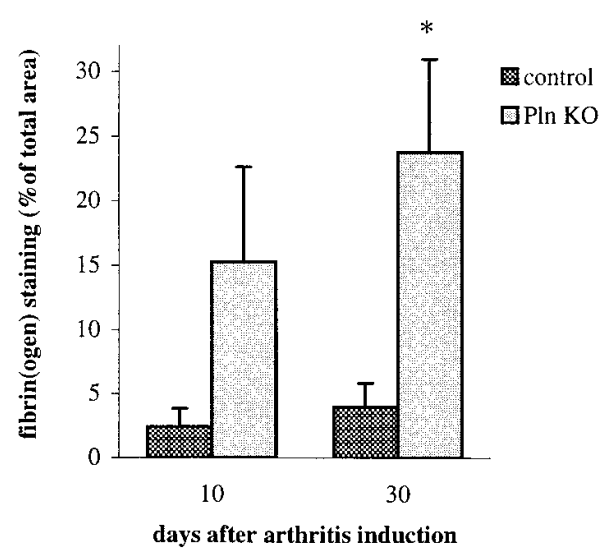

Figure 6. Quantification of fibrin deposition in arthritic knee joints. Fibrin accumulation has been evaluated in uPA-deficient $(a)$ and Pln-deficient (b) mice and in background-matched control mice. Fibrin immunohistochemical sections from four different mice for each condition were scanned. After drawing an area representing the joint cavity and the synovial membrane, the corresponding image was analyzed and the surface of immunoreactive areas

was determined and expressed as a percentage of the surface of the image examined. Results are expressed as the mean \pm SEM. Statistical significance was tested by using the Wilcoxon's rank sum test. $* P<0.05$ was considered significant.

sents one of the most striking pathologic features of rheumatoid synovitis $(8,18,19)$. In AIA, we also found large amounts of fibrin in the synovial membrane, on the cartilage surface, and in the synovial cavity of the arthritic knee, compared with the contralateral noninvolved knee joint, where it was almost undetectable. In RA patients, deposition of fibrin in arthritic joints could result from hyperfibrinogenemia (34) and from synovial microvascular hyperpermeability, leading to local extravasation of plasma fibrinogen. Then, the extravasated fibrinogen could be converted rapidly to fibrin. Indeed, immunohistochemical techniques have detected increased expression of tissue factor and tissue transglutaminase by intraarticular endothelial cells and macrophages, thus providing the ability to generate and cross-link fibrin in RA synovial tissues (8).

Extravascular fibrin deposition is a crucial event in other disease states characterized by inflammation and tissue repair. In animal models of septic shock (35), lung injury $(36,37)$, impaired wound healing (38), and glomerulonephritis (39), excessive fibrin deposition was associated with a marked reduction or a deficiency of PA-mediated proteolysis. In all these situations (apart from glomerulonephritis where tPA activity is prominent), failure to remove fibrin was attributable to reduced uPA-mediated fibrinolysis. In arthritis, we also found that uPA deficiency led to increased levels of synovial fibrin, thus stressing the importance of uPA in extravascular fibrin clearance. However, fibrin removal in arthritic joints could be partly due to nonplasmin proteolytic enzymes such as polymorphonuclear leukocyte elastase $(40,41)$.

Fibrin in the synovium and on the cartilage may have deleterious effects, such as the impediment of normal nutrition to these tissues leading to hypoxia and acidosis in synovial fluid (as suggested by Firestein in reference 1). In addition, fibrin(ogen) degradation products may have a proinflammatory role in the joint by increasing vascular permeability and inducing chemotaxis at sites of inflammation. Moreover, the extravascular fibrin meshwork may serve as a provisional matrix onto which cells can adhere and migrate (42 and references therein). Finally, intraarticular fibrin may enhance the local expression of the proinflammatory cytokine IL- $1 \beta$ by monocytes (43).
The link between increased fibrin levels and enhanced synovial inflammation was further explored by defibrinogenation of arthritic uPA-deficient mice. We showed that ancrod reduced plasma fibrinogen and intraarticular fibrin(ogen) deposition and substantially attenuated joint inflammation. These results clearly demonstrate that fibrin(ogen) has a role in sustaining joint inflammation and expand on an earlier work (44). The fact that defibrinogenation with ancrod did not totally abolish inflammation could be either because part of the inflammation is fibrin independent, or because the residual intraarticular fibrin is sufficient to sustain a basal level of inflammation. To discriminate between these two possibilities, it would be interesting to study AIA in mice with a combined deficiency in Pln and fibrinogen (Pln-/-; Fib-/- mice) (45). By this genetic approach, it has been possible to show that life expectancy and healing rates were dramatically improved in (Pln-/-; Fib-/-) mice compared with Pln-/- mice (45), whereas resistance to neurodegeneration was not changed in these double-deficient mice (46). These observations strongly suggest that in the two former phenotypes, the primary role of $\mathrm{Pln}$ is fibrinolysis, whereas in the latter, Pln acts on a nonfibrin substrate.

Our finding that loss of Pln activation promotes articular inflammation raises the question of whether plasmin-mediated proteolysis plays a general role in the inflammatory response. Many observations made using mice with specific deficits in Pln activation system components suggest that Pln activator/ plasmin may have a profound effect on inflammation and inflammation-related disease $(36,37,39,47)$. One particularly notable finding implying an important interplay between Pln activation and inflammatory disease is the recent observation that neointima formation is dramatically accelerated in atherosclerosis-prone, apo E-deficient mice when they also lack Pln (48). As suggested for arthritic disease, excessive or persistent fibrin deposition in Pln-deficient mice may promote local adhesion and migration of inflammatory cells, as well as stimulate the in-growth of medial smooth muscle cells into the intima. Interestingly, disruption of elastic lamina in the vessel wall of apoE-/- mice fed a high-fat diet was recently reported to be partially sensitive to the expression of uPA (49). 
Thus, plasmin may also participate in inflammatory cell-mediated proteolysis of nonfibrin extracellular substrates, probably via plasmin-dependent activation of MMPs.

Our experiments also provide some insights into the relative importance of the uPA/plasmin proteolytic pathway in joint destruction. As plasmin can mediate cartilage and bone destruction in vitro $(16,17)$, we expected that $\mathrm{uPA}-/-$ and Pln $-/-$ mice would have less severe signs of joint destruction. However, we observed no significant difference in cartilage proteoglycan depletion between uPA- and Pln-deficient mice and their corresponding controls. This lack of overt difference could indicate that plasmin is not involved in cartilage erosion, and that other classes of proteases may fulfill the crucial functions in the cartilage breakdown pathway. However, we cannot rule out that in the absence of plasmin an alternative pathway which compensates for the effects of plasmin is activated. In this context, the effect of IL-1 on cartilage has to be considered. This cytokine causes marked proteoglycan depletion mainly through inhibition of proteoglycan synthesis (50). The sustained inflammation in uPA-/- arthritic joints and the resultant enhanced levels of locally produced IL-1 may lead to IL-1-mediated inhibition of proteoglycan synthesis and to IL-1-enhanced production of cartilage-degrading MMPs (51). Definitive proof of the existence of this pathway awaits studies using neutralizing antibodies against IL-1 in uPA-/- mice. The exacerbation of bone destruction on day 30 of AIA in these mice may also be explained by increased production of proinflammatory cytokines in arthritic joints. Among them, IL-1-enhanced bone resorption is currently thought to be a major cause of bone damage in inflammatory diseases (52).

Finally, apart from its effects on extracellular matrix proteins, uPA/plasmin can cleave and activate latent forms of growth/angiogenic factors such as TGF- $\beta$ and hepatocyte growth factor $(3,53)$. Both factors are expressed within arthritic joints and are believed to have important pathogenic effects $(54,55)$. Therefore, modulation of uPA-mediated proteolytic activity may indirectly influence cell recruitment and the growth and differentiation of cellular constituents in arthritic joints, although this role remains to be demonstrated both in vitro and in vivo.

In conclusion, our results demonstrate that uPA fulfills a beneficial role in arthritis, mainly through uPA-mediated fibrinolytic activity. Compounds aimed at decreasing fibrin levels in joints may be clinically useful in RA therapy. Future experiments will be directed toward further definition of the benefit of defibrinogenating, anticoagulant, or fibrinolytic agents in this debilitating disease.

\section{Acknowledgments}

We thank the Nuclear Medicine Department of the CHUV (Dr. Angelika Bischof-Delaloye) for kindly providing ${ }^{99 \mathrm{~m}} \mathrm{Tc}$ and Dr. Pascal Sappino, Dr. Jean-Dominique Vassalli, and Dr. Mike Billingham for helpful discussions.

This work was supported by a grant from the Fonds National Suisse de la Recherche Scientifique and by the Jean and Linette Warnery Foundation.

\section{References}

1. Firestein, G.S. 1997. Etiology and pathogenesis of rheumatoid arthritis In Textbook of Rheumatology. W.N. Kelley, E.D. Harris, S. Ruddy, and C.B. Sledge, editors. W.B. Saunders Co., Philadelphia. 851-897.
2. Dano, K., P.A. Andreasen, J. Grondahl-Hansen, P. Kristensen, L.S. Nielsen, and L. Skriver. 1985. Plasminogen activators, tissue degradation, and cancer. Adv. Cancer Res. 44:139-266.

3. Vassalli, J.D., A.P. Sappino, and D. Belin. 1991. The plasminogen activator/plasmin system. J. Clin. Invest. 88:1067-1072.

4. Vassalli, J.D., D. Baccino, and D. Belin. 1985. A cellular binding site for the $M_{\mathrm{r}} 55,000$ form of the human plasminogen activator, urokinase. J. Cell Biol. 100:86-92.

5. Ossowski, L., G. Clunie, M.T. Masucci, and F. Blasi. 1991. In vivo paracrine interaction between urokinase and its receptor: effect on tumor cell invasion. J. Cell Biol. 115:1107-1112.

6. Hamilton, J.A., I.K. Campbell, J. Wojta, and D. Cheung. 1991. Plasminogen activators and their inhibitors in arthritic disease. Ann. NY Acad. Sci. 667: 87-100.

7. Busso, N., V. Péclat, A. So, and A.-P. Sappino. 1997. Plasminogen activation in synovial tissues: differences between normal, osteoarthritis, and rheumatoid arthritis joints. Ann. Rheum. Dis. 56:550-557.

8. Weinberg, J.B., A.M. Pippen, and C.S. Greenberg. 1991. Extravascular fibrin formation and dissolution in synovial tissue of patients with osteoarthritis and rheumatoid arthritis. Arthritis Rheum. 34:996-1005.

9. Ronday, H.K., H.H. Smits, G.N. van Muijen, M.S. Pruszcynski, R.J. Dolhain, E.J. van Langelaan, F.C. Breedveld, and J.H. Verheijen. 1996. Difference in expression of the plasminogen activation system in synovial tissue of patients with rheumatoid arthritis and osteoarthritis. Br. J. Rheumatol. 35:416-423.

10. Brommer, E.J., G. Dooijewaard, B.A. Dijkmans, and F.C. Breedveld. 1992. Depression of tissue-type plasminogen activator and enhancement of urokinase-type plasminogen activator as an expression of local inflammation. Thromb. Haemost. 68:180-184

11. Saxne, T., I. Lecander, and P. Geborek. 1993. Plasminogen activators and plasminogen activator inhibitors in synovial fluid. Difference between inflammatory joint disorders and osteoarthritis. J. Rheumatol. 20:91-96.

12. Belcher, C., F. Fawthrop, R. Bunning, and M. Doherty. 1996. Plasminogen activators and their inhibitors in synovial fluid from normal, osteoarthritis, and rheumatoid arthritis knees. Ann. Rheum. Dis. 55:230-236.

13. Werb, Z., and C.M. Alexander. 1993. Proteinases and Matrix Degradation. In Textbook of Rheumatology. W.N. Kelley, E.D. Harris, S. Ruddy, and C.B. Sledge, editors. W.B. Saunders Co., Philadelphia. 248-268.

14. Werb, Z., C.L. Mainardi, C.A. Vater, and E.D. Harris, Jr. 1977. Endogenous activation of latent collagenase by rheumatoid synovial cells. Evidence for a role of plasminogen activator. N. Engl. J. Med. 296:1017-1023.

15. Murphy, G., S. Atkinson, R. Ward, J. Gavrilovic, and J.J. Reynolds. 1992. The role of plasminogen activators in the regulation of connective tissue metalloproteinases. Ann. NY Acad. Sci. 667:1-12.

16. Campbell, I.K., D.S. Piccoli, M.J. Roberts, K.D. Muirden, and J.A. Hamilton. 1990. Effects of tumor necrosis factor alpha and beta on resorption of human articular cartilage and production of plasminogen activator by human articular chondrocytes. Arthritis Rheum. 33:542-552.

17. Ronday, H.K., H.H. Smits, P.H.A. Quax, G. Van Der Pluijm, C.W.G.M. Làwik, F.C. Breedveld, and J.H. Verheijen. 1996. Bone matrix degradation by the plasminogen activation system. Possible mechanism of bone destruction in arthritis. Br. J. Rheumatol. 36:9-15.

18. Jasani, M.K. 1978. Fibrin: metabolism, immunopathogenesis and significance in rheumatoid arthritis. In Immunopathogenesis of Rheumatoid Arthritis. G.S. Panayi and P.M. Johnson, editors. Red Books, Surrey. 137-146.

19. Zacharski, L.R., F.E. Brown, V.A. Memoli, W. Kisiel, B.J. Kudryk, S.M Rousseau, J.A. Hunt, C. Dunwiddie, and E.M. Nutt. 1992. Pathways of coagulation activation in situ in rheumatoid synovial tissue. Clin. Immunol. Immunopathol. 63:155-162.

20. Collen, D., and H.R. Lijnen. 1992. Fibrin-specific fibrinolysis. Ann. NY Acad. Sci. 667:259-271.

21. Rabbani, S.A., A.P. Mazar, S.M. Bernier, M. Haq, I. Bolivar, J. Henkin, and D. Goltzman. 1992. Structural requirements for the growth factor activity of the amino-terminal domain of urokinase activity. FEBS Lett. 267:1415114156.

22. Busso, N., S.K. Masur, D. Lazega, S. Waxman, and L. Ossowski. 1994 Induction of cell migration by pro-urokinase binding to its receptor: possible mechanism for signal transduction in human epithelial cells. J. Cell Biol. 126: 259-270.

23. Waltz, D.A., and H.A. Chapman. 1994. Reversible cellular adhesion to vitronectin linked to urokinase receptor occupancy. J. Biol. Chem. 269:1474614750.

24. Carmeliet, P., L. Schoonjans, L. Kieckens, B. Ream, J. Degen, R. Bronson, R. De Vos, J.J. van den Oord, D. Collen, and R.C. Mulligan. 1994. Physiological consequences of loss of plasminogen activator gene function in mice. Nature. 368:419-424.

25. Bugge, T.H., M.J. Flick, C.C. Daugherty, and J.L. Degen. 1995. Plasminogen deficiency causes severe thrombosis but is compatible with development and reproduction. Genes Dev. 9:794-807.

26. Bugge, T.H., K.W. Kombrinck, Q. Xiao, K. Holmbäck, C.C. Daugherty, D.P. Witte, and J.L. Degen. 1997. Growth and dissemination of Lewis lung carcinoma in plasminogen-deficient mice. Blood. 90:4522-4531.

27. Brackertz, D., G.F. Mitchell, and I.R. Mackay. 1977. Antigen-induced 
arthritis in mice. I. Induction of arthritis in various strains of mice. Arthritis Rheum. 20:841-850.

28. Sappino, A.P., J. Huarte, J.D. Vassalli, and D. Belin. 1991. Sites of synthesis of urokinase and tissue-type plasminogen activators in the murine kidney. J. Clin. Invest. 87:962-970.

29. Meacock, S.C., D.R. Brandon, C.P. Brown, and B.P. Swann. 1992. A novel technique for immunohistoperoxidase staining of unfixed whole joints of small animals. Histochem. J. 24:115-119.

30. Vassalli, J.D., and D. Belin. 1987. Amiloride selectively inhibits the urokinase-type plasminogen activator. FEBS Lett. 214:187-191.

31. Kleiner, D.E., and W.G. Stetler-Stevenson. 1994. Quantitative zymography: detection of picogram quantities of gelatinases. Anal. Biochem. 218:325-329.

32. Kruijsen, M.W., W.B. van den Berg, L.B. Van De Putte, and W.J. van den Broek. 1981. Detection and quantification of experimental joint inflammation in mice by measurement of ${ }^{99 \mathrm{~m}}$ Tc-pertechnetate uptake. Agents Actions. 11: 640-642.

33. Bell, W.R., S.S. Shapiro, J. Martinez, and H.L. Nossel. 1978. The effects of ancrod, the coagulating enzyme from the venom of Malayan pit viper $(A$. Rhodostoma) on prothrombin and fibrinogen metabolism and fibrinopeptide A release in man. J. Lab. Clin. Med. 91:592-604.

34. Takeda, Y. 1969. Studies of the metabolism and distribution of fibrinogen in patients with rheumatoid arthritis. J. Lab. Clin. Med. 69:624-633.

35. Yamamoto, K., and D.J. Loskutoff. 1996. Fibrin deposition in tissues from endotoxin-treated mice correlates with decreases in the expression of urokinase-type but not tissue-type plasminogen activator. J. Clin. Invest. 97: $2440-2451$

36. Eitzman, D.T., R.D. McCoy, X. Zheng, W.P. Fay, T. Shen, D. Ginsburg, and R.H. Simon. 1996. Bleomycin-induced pulmonary fibrosis in transgenic mice that either lack or overexpress the murine plasminogen activator inhibitor-1 gene. J. Clin. Invest. 97:232-237.

37. Barazzone, C., D. Belin, P.-F. Piguet, J.-D. Vassalli, and A.-P. Sappino. 1996. Plasminogen activator inhibitor-1 in acute hyperoxic mouse lung injury. $J$. Clin. Invest. 98:2666-2673.

38. Romer, J., T.H. Bugge, C. Pyke, L.R. Lund, M.J. Flick, J.L. Degen, and K. Dano. 1996. Impaired wound healing in mice with a disrupted plasminogen gene. Nat. Med. 2:287-292.

39. Kitching, A.R., S.R. Holdsworth, V.A. Ploplis, E.F. Plow, D. Collen, P. Carmeliet, and P.G. Tipping. 1997. Plasminogen and plasminogen activators protect against renal injury in crescentic glomerulonephritis. J. Exp. Med. 185: 963-968.

40. Carmassi, F., F. De Negri, M. Morale, R. Puccetti, and S.I. Chung. 1994. Elastase- and plasmin-mediated fibrinolysis in rheumatoid arthritis. Int. J. Tissue React. 16:89-93.

41. Bos, R., C.J. van Leuven, J. Stolk, P.S. Hiemstra, H.K. Ronday, and W. Nieuwenhuizen. 1997. An enzyme immunoassay for polymorphonuclear leucocyte-mediated fibrinogenolysis. Eur. J. Clin. Invest. 27:148-156.

42. Suh, T.T., K. Holmback, N.J. Jensen, C.C. Daugherty, K. Small, D.I. Simon, S. Potter, and J.L. Degen. 1995. Resolution of spontaneous bleeding events but failure of pregnancy in fibrinogen-deficient mice. Genes Dev. 9:
2020-2033.

43. Perez, R.L., and J. Roman. 1995. Fibrin enhances the expression of IL-1 beta by human peripheral blood mononuclear cells. Implications in pulmonary inflammation. J. Immunol. 154:1879-1887.

44. Dumonde, D.C., and L.E. Glynn. 1962. The production of arthritis in rabbits by an immunological reaction to fibrin. Br. J. Exp. Pathol. 43:373-383.

45. Bugge, T.H., K.W. Kombrinck, M.J. Flick, C.C. Daugherty, M.J.S. Danton, and J.L. Degen. 1996. Loss of fibrinogen rescues mice from the pleiotropic effects of plasminogen deficiency. Cell. 87:709-719.

46. Tsirka, S.E., T.H. Bugge, J.L. Degen, and S. Strickland. 1997. Neuronal death in the central nervous system demonstrates a non-fibrin substrate for plasmin. Proc. Natl. Acad. Sci. USA. 94:9779-9781.

47. Gyetko, M.R., G.-H. Chen, R.A. McDonald, R. Goodman, G.B. Huffnagle, C.C. Wilkinson, J.A. Fuller, and G.B. Toews. 1996. Urokinase is required for the pulmonary inflammatory response to Cryptococcus neoformans. J. Clin. Invest. 97:1818-1826.

48. Xiao, Q., M.J.S. Danton, D.P. Witte, M.C. Kowala, M.T. Valentine, T.H. Bugge, and J.L. Degen. 1997. Plasminogen deficiency accelerates vessel wall disease in mice predisposed to atherosclerosis. Proc. Natl. Acad. Sci. USA 94:10335-10340.

49. Carmeliet, P., L. Moons, R. Lijnen, M. Baes, V. Lemaitre, P. Tipping, A Drew, Y. Eeckhout, S. Shapiro, F. Lupu, and D. Collen. 1997. Urokinase-generated plasmin activates matrix metalloproteases during aneurism formation. Nat. Genet. 17:439-444.

50. van den Berg, W.B., F.A.J. van den Loo, P.L.E.M. van Lent, and L.A.B Joosten. 1993. Mechanisms of cartilage destruction in joint inflammation. Agents Actions. 39:49-60.

51. Martel-Pelletier, J., R. McCollum, N. Fujimoto, K. Obata, J.M. Cloutier, and J.P. Pelletier. 1994. Excess of metalloproteases over tissue inhibitor of metalloprotease may contribute to cartilage degradation in osteoarthritis and rheumatoid arthritis. Lab. Invest. 70:807-815.

52. Konig, A., R.C. Muhlbauer, and H. Fleisch. 1988. Tumor necrosis factor alpha and interleukin-1 stimulate bone resorption in vivo as measured by urinary $(3 \mathrm{H})$ tetracycline excretion from prelabeled mice. J. Bone Miner. Res. 3: 621-627.

53. Naldini, L., L. Tamagnone, E. Vigna, M. Sachs, G. Hartmann, W. Birchmeier, Y. Daikuhra, Y. Tsubouchi, F. Blasi, and P.M. Comoglio. 1992. Extracellular proteolytic cleavage by urokinase is required for activation of hepatocyte growth factor/scatter factor. EMBO (Eur. Mol. Biol. Organ.) J. 11:4825-4833.

54. Taketazu, F., M. Kato, A. Gobl, H. Ichijo, P. ten Dijke, J. Itoh, M. Kyogoku, J. Ronnelid, K. Miyazono, C.H. Heldin, et al. 1994. Enhanced expression of transforming growth factor-beta s and transforming growth factor-beta type II receptor in the synovial tissues of patients with rheumatoid arthritis. Lab. Invest. 70:620-630.

55. Koch, A.E., M.M. Halloran, S. Hosaka, M.R. Shah, C.J. Haskell, S.K. Baker, R.J. Panos, G.K. Haines, G.L. Bennett, R.M. Pope, and N. Ferrara 1996. Hepatocyte growth factor. A cytokine mediating endothelial migration in inflammatory arthritis. Arthritis Rheum. 39:1566-1575. 